Dr Kent receives personal fees from LivaNova. Dr Fedak has nothing to disclose with regard to commercial support.

2. Nair SK, Sudarshan CD, Thorpe BS, Singh J, Pillay T, Catarino P, et al. Mini-Stern trial: a randomized trial comparing mini-sternotomy to full median sternotomy for aortic valve replacement. J Thorac Cardiovasc Surg. 2018;156:2124-32.e31.

3. Fedak PW. Make sternotomy great again. J Thorac Cardiovasc Surg. 2019;156:2133-4.

4. Lamelas J. Minimally invasive aortic valve replacement: the "Miami method" Ann Cardiothorac Surg. 2015:4:71-7.

5. Glauber M, Miceli A, Gilmanov D, Ferrarini M, Bevilacqua S, Farneti PA, et al. Right anterior minithoracotomy versus conventional aortic valve replacement: a propensity score matched study. J Thorac Cardiovasc Surg. 2013;145:1222-6.

6. Fedak PW, Kieser TM, Maitland AM, Holland M, Kasatkin A, Leblanc P, et al. Adhesive-enhanced sternal closure to improve postoperative functional recovery: a pilot, randomized controlled trial. Ann Thorac Surg. 2011;92:1444-50.

7. US National Library of Medicine. NCT03365843: Montage-Enhanced Sternal Closure. Available at: https://clinicaltrials.gov/ct2/show/NCT03365843. Accessed May 1, 2018

https://doi.org/10.1016/j.jtcvs.2019.02.018

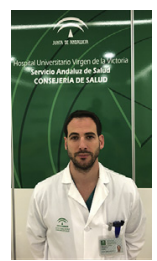

\section{MORE EVIDENCE FAVORING BIOPROSTHESES FOR PATIENTS OLDER THAN 55 YEARS IN AORTIC VALVE REPLACEMENT \\ To the Editor:}

I read with great interest the recently published meta-analysis of Diaz and colleagues, ${ }^{1}$ which establishes that relative to biologic valves, mechanical prostheses provide a survival benefit for patients aged 50 to 70 years who undergo aortic valve replacement (4886 patients from 5 studies).

I believe that this study has a number of important limitations that should be highlighted. The first one is due to its design. The protocol that was published in the PROSPERO database (registry number CRD42017076611) established as inclusion criteria only propensity score-matched (PSM) studies or randomized controlled trials. This design prevented the inclusion of the study by Goldstone and associates, ${ }^{2}$ the largest study published to date (9942 patients), because confounding variables were controlled by inverse probability-weighted cohorts. This work showed no differences in survival for patients older than 55 years. Likewise, age subgroup analysis were not carried out with this age cutoff in the meta-analysis.

It is important to note that the use of propensity score matching can only control for previously measured and registered variables. Unmeasured or unknown factors thus may still be different between groups after matching. These confounding factors could potentially introduce bias favoring the mechanical group, because surgeons tended to implant bioprostheses in patients younger than 65 years
Author has nothing to disclose with regard to commercial support.

only if those patients are considered frail candidates (those with a reduced life expectancy, high comorbidities, or contraindication for anticoagulation) or in cases of patient preference.

Importantly, there must be factors that influence the risk of structural valve degeneration or thrombosis, or that affect the control of anticoagulation. In this sense, the percentage of international normalized ratio self-monitoring (which reduces international normalized ratio variability and clinical events), ${ }^{3}$ the type and size of implanted prosthesis, or a diet rich in vegetables, such as the Mediterranean diet, thus are factors that have not yet been properly studied. I therefore believe that knowing the real-world results in different regions or countries provides more knowledge than a weighted average of all the studies, because the environment exerts an influence impossible to quantify.

Recently, my group has led the Andalousian Aortic Valve Multicentric (ANDALVALVE) Study, ${ }^{4}$ a multicentric retrospective study including all subjects aged 50 to 65 years who underwent primary isolated aortic valve replacement for severe aortic stenosis at all hospitals within Andalusia, Spain (population, 8,500,000 people) between 2000 and 2015. A total of 1443 patients were enrolled. After propensity score matching, our study showed similar long-term survivals for patients older than 55 years. A National extension comprising 30 hospitals in Spain is underway (SPAVALVE, ClinicalTrials.gov NCT03595423]).

\section{Emiliano A. Rodríguez-Caulo, MD, PhD, FETCS \\ Heart Area \\ Cardiovascular Surgery Division University Hospital Virgen de la Victoria Málaga, Spain CIBERCV Cardiovascular Diseases Health Institute Carlos III Madrid, Spain}

\section{References}

1. Diaz R, Hernandez-Vaquero D, Alvarez-Cabo R, Avanzas P, Silva J, Moris C, et al Long-term outcomes of mechanical versus biological aortic valve prosthesis: systematic review and meta-analysis. J Thorac Cardiovasc Surg. November 20, 2018 [Epub ahead of print]

2. Goldstone AB, Chiu P, Baiocchi M, Lingala B, Patrick WL, Fischbein MP, et al. Mechanical or biologic prostheses for aortic-valve and mitral-valve replacement N Engl J Med. 2017;377:1847-57.

3. Baumgartner H, Falk V, Bax JJ, De Bonis M, Hamm C, Holm PJ, et al; ESC Scientific Document Group. 2017 ESC/EACTS guidelines for the management of valvular heart disease. Eur Heart J. 2017;38:2739-91.

4. Rodríguez-Caulo EA, Macías D, Adsuar A, Ferreiro A, Arias-Dachary J, Parody G, et al. Biological or mechanical prostheses for isolated aortic valve replacement in patients aged 50-65 years: the ANDALVALVE study. Eur J Cardiothorac Surg. 2019; https://doi.org/10.1093/ejcts/ezy459 [Epub ahead of print]. 